\title{
Core Topics in Mechanical Ventilation
}

\section{Iain Mackenzie (ed). Cambridge University Press, Cambridge, UK, 2008, 425 pp, ISBN 978-0-521-86781-8}

\author{
Michael J. Jacka, MD
}

Published online: 29 July 2009

(c) Canadian Anesthesiologists' Society 2009

This text encompasses a wide-ranging review of the physiology and pathophysiology of respiratory failure, its supportive therapy, and the mechanisms of effect of supportive therapy. The topics include basic discussions regarding the physiology of gas exchange, impairment of gas exchange, mechanical support of respiratory failure, and the use of ancillary support, including nutrition, sedation, and muscle relaxation.

The skillfully depicted graphics in the textbook facilitate comprehension of the topics discussed, and are likely easier for the trained reader to understand than representations in larger and more costly reference books. An appropriate use of colour and font is used consistently in the illustrations throughout the text.

Unfortunately, the writing style frequently mimics casual conversation, which may be appropriate for an oral presentation but is incongruous for a textbook. This is typified by 'wordiness', redundant comparisons, and digressions that significantly detract the reader from comprehending the text. These distractions in the text would present the untrained reader with unnecessary difficulty.

Although the preface indicates that the text was intended as a concise and practical overview of the topic, this objective is met primarily for the trained reader in terms of the illustrations. Regrettably for the untrained reader, the text's wordiness presents a challenge in differentiating between important and less important passages. If readers desire a concise focused review, they should consider another handbook on the topic; alternatively a comprehensive review text would remain appropriate. 